\title{
El Osireion de Oxirrinco (EI Bahnasa, Egipto)
}

Maite MASCORT ROCA

En el año 2000 se descubrió, al oeste de la ciudad grecorromana de Oxirrinco, una serie de estructuras subterráneas consagradas a Osiris. Bajo una elevación natural del terreno se ha iniciado la excavación de un recinto cultual presidido por una estatua colosal del dios y, adyacente a esta sala, un pasillo donde se enterraban los simulacros de Osiris que se realizaban con motivo del ritual de los misterios del mes de Khoiak.

En las dos últimas campañas los trabajos se han centrado en la superestructura del monumento. Se ha localizado el témenos, pudiendo, así, delimitar toda el área del recinto sagrado. Se ha excavado, también, la entrada monumental por la que se accedía al interior de la catacumba. Delante de la entrada, una serie de estructuras nos revelan una zona donde se realizaban las ofrendas diarias a la divinidad. Hasta el momento, podemos fechar el conjunto en época ptolemaica.

\section{The Osireion of Oxyrhynchus (El Bahnasa, Egipto)}

In the year 2000, a series of underground structures dedicated to Osiris were discovered to the west of the Graeco-Roman city of Oxyrhynchus. Beneath a natural slope in the land, excavation was started of an enclosure used for worship, presided over by a colossal statue of the god. Next to this chamber was a passage where the figurines of Osiris that were made to be used in the ritual mysteries of the month of Khoiak were buried.

In the last two campaigns, work has concentrated on the superstructure of the monument. The temenos had been located thus allowing the limits of the area used for worship to be delineated. The monumental entrance which gave access to the interior of the catacomb has also been excavated. In front of the entrance there is a series of structures that reveal an area where daily offerings were made to the divinity. So far we can date the complex to the Ptolemaic period.

KEY wORDs: Oxyrhynchus, Khoiak, Osireion

$1,5 \mathrm{~km}$ al oeste de la necrópolis saíta, en una
zona conocida popularmente como el templo de Ramsés, del que sólo quedan unos bloques dispersos de caliza blanca, se localizó en el año $2000^{1}$ una serie de cámaras subterráneas pertenecientes a un complejo cultual dedicado a Osiris.

1. El templo-necrópolis de Osiris fue localizado por los ladrones. Éstos fueron descubiertos por la policía en el momento de querer robar la estatua de Osiris.

Fecha de recepción: 20 de enero de 2007

Fecha de aceptación: 25 de junio de 2007

http://doi.org/10.25145/j.TdE.2009.05.02.06 
En el año 2001 se iniciaron los trabajos de la misión española-egipcia dirigida por el Dr. J. Padró$^{2}$. Durante dos campañas se ha trabajado en el interior de la subestructura de un templo-necrópolis dedicado a Osiris, pero, por problemas estructurales, debidos a la mala calidad de la roca natural y a la débil consistencia del terreno, en las campañas de 2004 y 2005 se han centrado los esfuerzos en la excavación de la superestructura del monumento, mientras los arquitectos proceden a la restauración y consolidación de las estructuras subterráneas ${ }^{3}$.

Este Osireion, el Abatón oxirrinquita de cuya existencia no se tenía constancia, está constituido, hasta el momento, por dos cámaras y una galería excavadas en la roca. La elevación natural de esta zona del desierto sugiere la colina primigenia que recubre y protege la tumba de Osiris y la existencia de otros elementos de culto construidos en la superficie. Este coherente conjunto de estructuras estaría, probablemente, relacionado con un templo hoy desaparecido denominado $\operatorname{Pr}-h f$.

El recinto fue ampliamente reestructurado durante los reinados de Alejandro II Aegos, hijo de Alejandro Magno, Ptolomeo I Soter y Ptolomeo II Filadelfo; así lo atestiguan los diversos bloques hallados por los saqueadores hacía los años cincuenta del siglo pasado, decorados con relieves y textos jeroglíficos con el nombre de su lugar de procedencia: Pr-hf. Dichos bloques

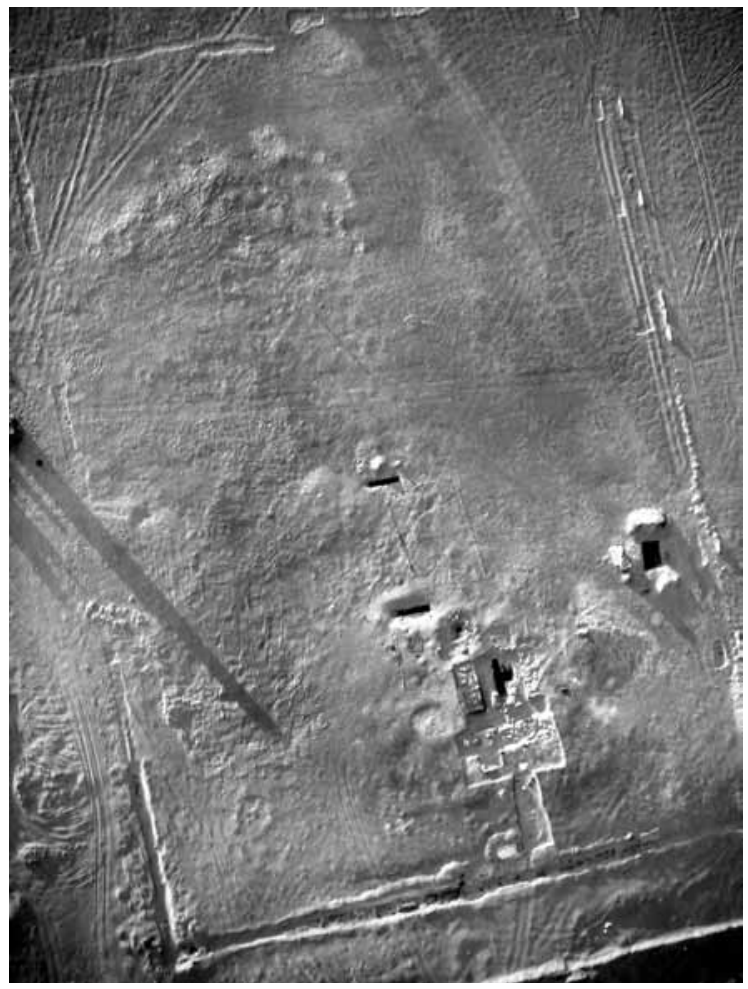

Figura 1. Foto aérea del área del Osireion

han sido posteriormente dispersados por Europa, localizándose algunos de ellos en los museos de Leiden (Holanda), Besançon (Francia) y en colecciones particulares de Suiza ${ }^{4}$.

En el exterior del yacimiento, la excavación ha consistido en poner al descubierto los restos de la superestructura del monumento, vestigios ya intuidos al estudiar con precisión las fotografias aéreas realizadas en el lugar ${ }^{5}$. La excavación ha

2. En el Osireion han intervenido los siguientes miembros de la Misión: Arqueólogos-egiptólogos: Hassan Amer Ibrahim, Marguerite Erroux Morfin, José Javier Martínez, Ma. Luz Mangado y Maite Mascort. Restauradores: Roger Xarrié y Bernat Burgaya, Topógrafo: Antonio López. Arquitectos: Fernando Estrada e Idoia Camiruaga. Epigrafista: Lauren Coulon.

3. Estas actuaciones se han llevado a cabo gracias al contrato-programa para la potenciación de la difusión de la Misión Arqueológica de Oxirrinco (Minia) 2004-2006 suscrito por la UB, URV e ICAC.

4. Sauneron, 1957: 51; Sauneron, 1968: 24-27. La última publicación de los dos bloques de Leiden se ha efectuado con motivo de la exposición Cleopatra's Egypt (VVAA, 1998: 100-101): dim. 36 x 142 cm, núm. Inventario: F1961/12.3; Dewachter, 1983: 45-50; Rondot, 1997: 274-278; Padró, Amer, Erroux- Morfin, Mascort, Hamza, 2007: 1443-1454.

5. Las fotografías aéreas con cometa han sido realizadas por los señores Yves Guichard y Thomas Sagory. 
confirmado las primeras hipótesis con la localización de la muralla que rodea el recinto del Osireion, así como la puerta monumental de entrada a las galerías subterráneas (fig. 1).

El témenos queda configurado por un muro de 1,60 $\mathrm{m}$ de anchura compuesto de bloques de adobe de $30 \times 15 \mathrm{~cm}$, que rodea el conjunto cultual. Mide $165 \mathrm{~m}$ en los lados norte y sur por 105 $\mathrm{m}$ en los lados este y oeste. Delimita un área de $17.325 \mathrm{~m}^{2}$, superficie mucho mayor a la prevista en un inicio, durante las prospecciones previas. Visto desde el exterior, y en la dirección esteoeste, parece que comprende dos elevaciones naturales del terreno. La muralla está muy deteriorada y se encuentra destruida en varios puntos de su perímetro.

Los ángulos de este muro de cierre quedan bien delimitados y están reforzados con adobes. En el ángulo sureste, se ha localizado un pozo de más de $5 \mathrm{~m}$ de profundidad, de boca cuadrada y no más de $1 \mathrm{~m}$ de anchura, que rompe el trazado del muro. Ello demuestra que se construyó en un periodo posterior, probablemente en época romana. En la parte inferior del pozo aparecieron sillares y piezas de decoración arquitectónica. En alguna de ellas, el diseño de estrías convergentes, a modo de conchas, permite su datación en la época romano-cristiana. Es razonable relacionar este pozo con el abastecimiento de agua, necesaria también para las ceremonias rituales relacionadas con la llegada de la inundación.

En el ángulo NO, entre el límite del muro y el terreno natural, se localizaron el cuello y algunos fragmentos del asa de una ánfora de época tardía (late roman $)^{6}$ tapada con un bloque de adobe. En el interior, no se encontró ningún material ni resto apreciable de sustancia.
La entrada al recinto se practicaría por el este del témenos. Diversos bloques de piedra caliza blanca adosados a la muralla, en un punto donde se cierra el trazado, parecen indicar el lugar de la puerta. En este sector se ha exhumado un ostracon con escritura demótica ${ }^{7}$, un plato de ofrendas y una moneda de época ptolemaica. Destacamos también algunos fragmentos de cerámica, pertenecientes al mismo periodo que la moneda, y restos de un ánfora rodia de cronología que abarca desde el siglo II a. C. hasta el cambio de Era.

La puerta estaba orientada hacia el pueblo y los templos, de donde venían las procesiones de sacerdotes que, supuestamente, transportaban los simulacros de Osiris durante las fiestas de los Misterios del mes de Khoiak $^{8}$.

Desde la entrada, subiendo una ligera pendiente, se llega a una zona donde las fotos aéreas indican una alteración importante del terreno. Excavado este espacio, han aparecido las estructuras que se detallan a continuación. Cerca de la entrada, una plataforma rectangular de adobe recubierta de un estrato de pequeñas lascas de piedra de caliza, que creemos puede tratarse del basamento de una pequeña capilla. Un conjunto de bloques de caliza blanca, cincelados a modo de losas, parecen indicar los restos de un pavimento que cubriría el área, así como un pebetero de caliza, para la realización de libaciones. También, un altar cuadrangular de adobes con evidentes signos de haber sido utilizado y numerosos fuegos, con restos de ceniza y alimentos pertenecientes a las ofrendas realizadas en esta parte. Se han podido identificar algunos de los productos: uvas, melocotones, frutos de persea ${ }^{9}$ y dátiles ${ }^{10}$. Igualmente han aparecido tapones de ánforas de vino, algunos con vestigios de sellos.

6. Las ánforas late roman tienen una cronología de los ss. IV-VII d.C.

7. En estudio.

8. Chassinat, 1966-68. 


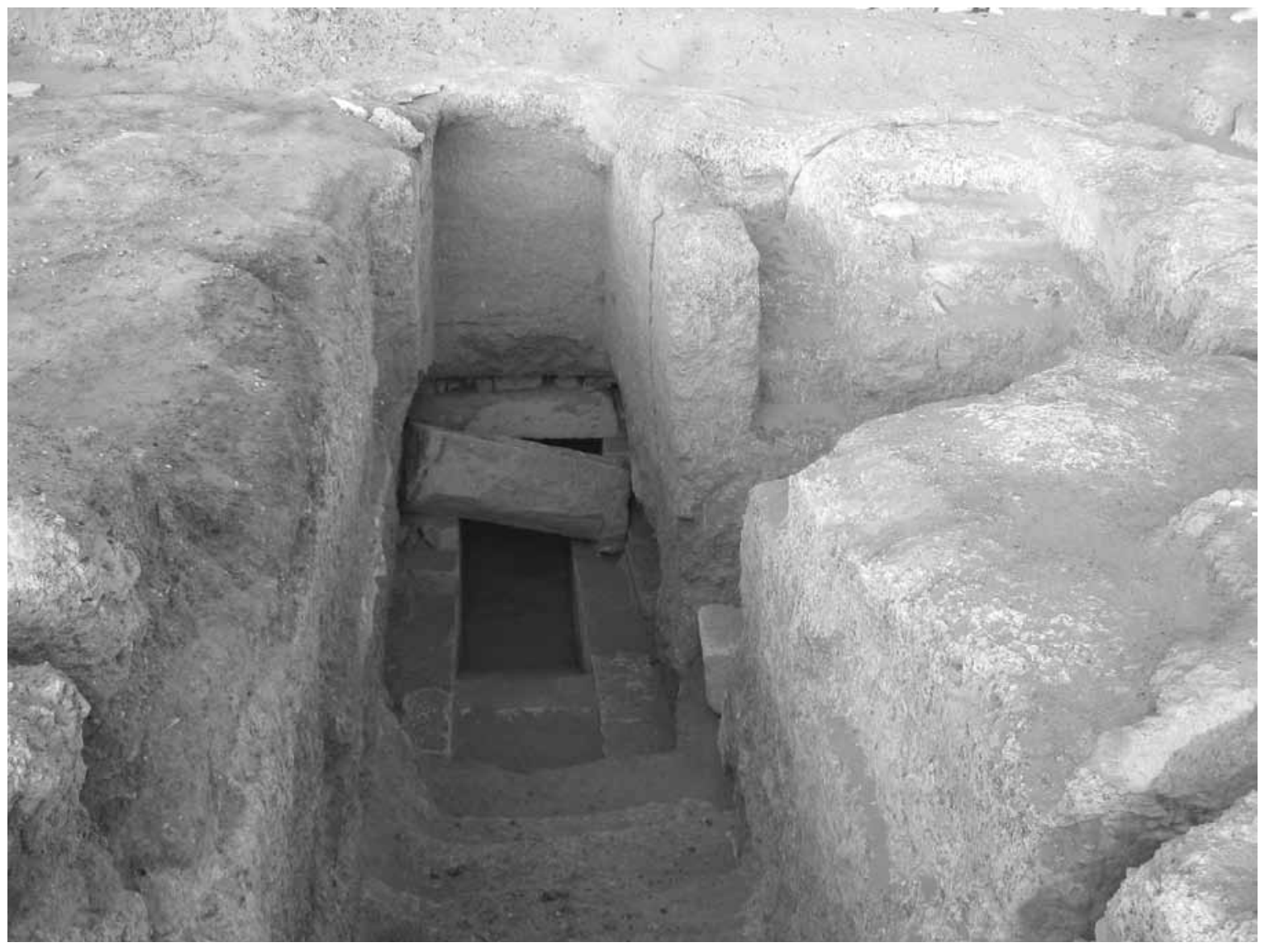

Figura 2. Entrada principal a las catacumbas osiriacas

Podemos afirmar que nos encontramos en una zona donde se realizaban las ofrendas rituales diarias en favor de Osiris.

Esta zona da acceso a una estructura más importante. Un pequeño templo en forma de $\mathrm{T}$ invertida, de unos $15 \mathrm{~m}$ de ancho por 15 de largo [80] del que apenas sobresalen $50 \mathrm{~cm}$ en su punto más alto, mientras que en otros puntos está totalmente arrasado.

Toda la construcción, que posiblemente estaría edificada con muros de adobe, se asienta en una banqueta tallada en la roca natural. Así en el sector norte sólo se aprecia el recorte de la banqueta mientras que en el lado sur son visibles muros de adobe de $50 \mathrm{~cm}$ de altura. En la esquina del muro del lado sureste apareció un ladrillo de fundación de $4 \mathrm{~cm}$ de largo por 2 de ancho. En este mismo ángulo, sobre la roca, encontramos un lecho de limo con improntas de una mano.

La aparición, en diversos puntos del templo, de enlosado pétreo hace pensar que toda su superficie estaba pavimentada con bloques de caliza blanca. Inserta en el centro de este pequeño santuario en

9. La persea está relacionada con el culto de Osiris. Sus frutos maduran en el momento de la crecida del Nilo: Bonneau, 1964: 62-67.

10. Cauville, 1982: 47-64. 


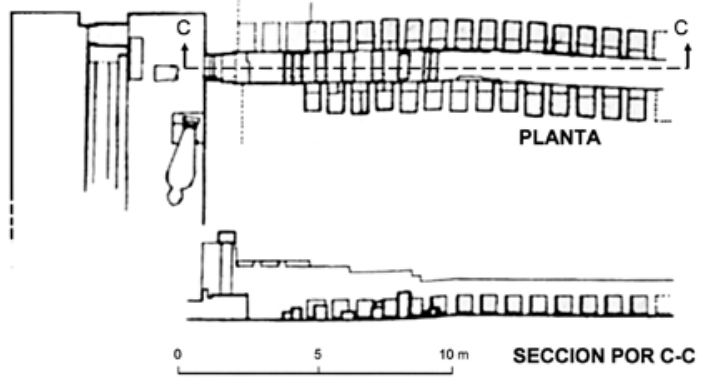

Figura 3. Planta del Osireion

forma de $\mathrm{T}$ invertida se encuentra la entrada a las galerías subterráneas. Esta entrada (fig. 2), que de momento consideraremos principal, está compuesta por una serie de peldaños tallados en la roca, y recubiertos con bloques calizos hoy desaparecidos. Los últimos nueve peldaños se construyeron con sillares de piedra caliza tallada. Al final de esta escalera, se configura el pasillo con techo de losas de la misma piedra de grandes dimensiones colocadas como arquitrabes. Finalizados los escalones de bajada, dos pequeños nichos practicados en las paredes laterales servían para alojar las lucernas utilizadas para iluminar el acceso al recinto subterráneo. Las partes superiores de estas oquedades aparecen manchadas de negro a consecuencia del humo de las mechas.

Ya en el exterior, y en la parte lateral derecha (mirando a la entrada), se aprecian dos pequeñas escaleras auxiliares talladas en la roca, que

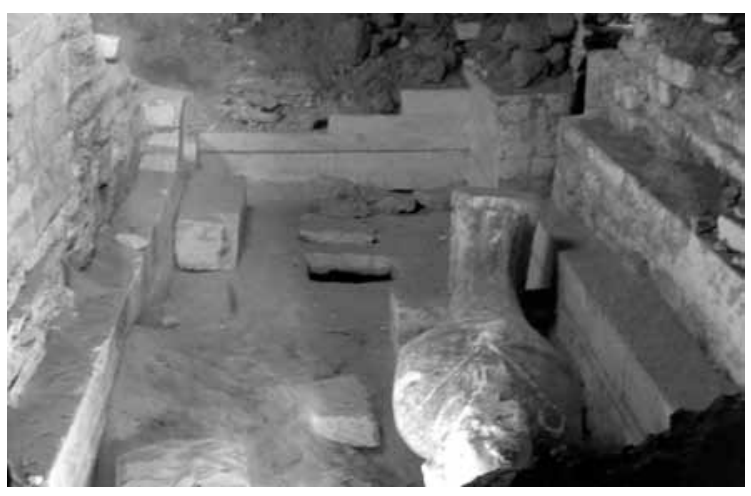

Figura 4. Sala de Osiris debían cumplir una función ritual todavía difícil de precisar.

Al norte del acceso se ha localizado una estructura cuadrada, excavada en la roca virgen, de $4 \mathrm{~m}$ de lado que corresponde a un pequeño lago. Los textos hacen referencia a diversas ceremonias rituales que tenían lugar en los lagos sagrados de los templos.

Durante las campañas de los años 2002 y 2003 se procedió a la excavación y limpieza de la subestructura del monumento compuesta, hasta el momento, de dos cámaras contiguas, una de las cuales alberga una gran estatua de Osiris. Desde esta sala se accede a un pasillo con nichos a ambos lados. Todo el recinto se encontraba revuelto y con daños estructurales importantes, debido al sistemático expolio de bloques de piedra tallada y a la reiterada presencia de ladrones (fig. 3).

Dos toscas escaleras, separadas $23,30 \mathrm{~m}$, permiten el acceso a una galería con dirección este-oeste de $29 \mathrm{~m}$ de longitud. Dichas escaleras, sin duda, fueron utilizadas durante la excavación del hipogeo.

Esta galería comunica por su extremo este con las dos cámaras forradas con bloques calizos. A media altura se observan líneas horizontales de pintura roja que servirían de guía a los jeroglíficos que nunca llegaron a inscribirse. El muro que separa las dos salas tiene en la parte inferior una decoración grabada de fachada de palacio. El suelo de losas calizas, es en realidad un pavimento flotante que, reposando sobre bloques alineados, permite disponer de un escondrijo compartimentado, accesible levantando las losas del pavimento.

En la cámara más occidental antiguamente cubierta con una bóveda de cañón (fig. 4), a juzgar 


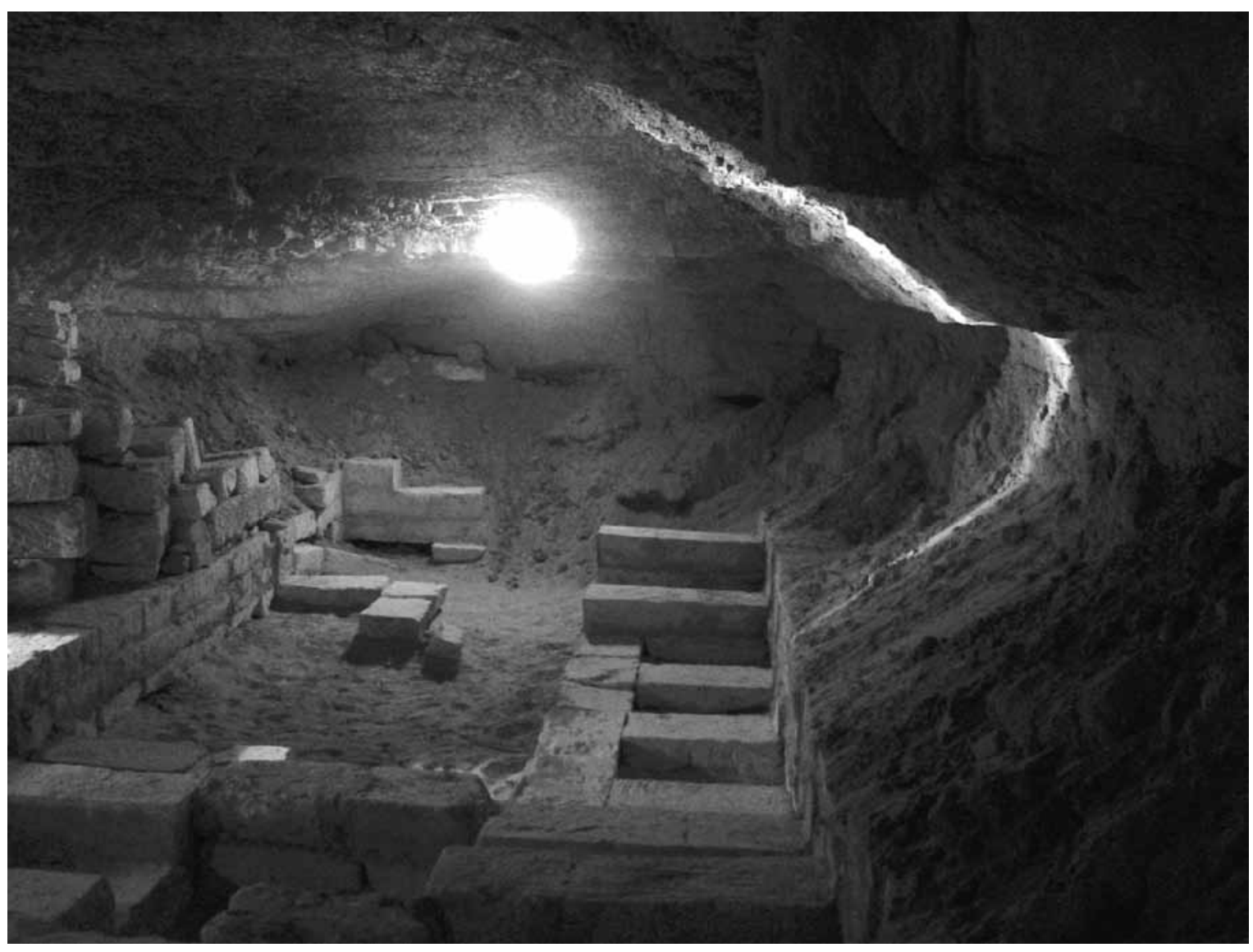

Figura 5. Galería de nichos

por la curvatura de la hilada de arranque, reposa la estatua yaciente de Osiris, de 3,30 m de longitud. La imagen del dios, esculpida en un bloque calizo, presentaba un color negro algo degradado, el color de la regeneración. Lleva los atributos propios de la divinidad: el cuerpo amortajado, las manos sosteniendo el heqa y el nejaja. La cabeza, hoy desfigurada, está tocada con la corona atef. En esta estancia, presidida por la colosal estatua, se rendía culto a Osiris.

La zona oriental todavía no se ha excavado. Se accede a ella mediante una puerta abierta en el ángulo sureste del conjunto. Una bóveda de bloques calizos, hoy desaparecida, cubría la estancia. El techo natural actual semejante al de una gruta, tiene dos aberturas cenitales de ventilación e iluminación.
Desde la "sala de Osiris" se accede a la galería de los nichos. Antiguamente, una puerta independizaba la sala de la galería. Esta última, que fue construida en diversas etapas, está recubierta con bloques tallados y ensamblados de caliza blanca. A juzgar por los restos encontrados, el pasillo estaba cubierto con grandes losas, de manera similar a la entrada monumental de la catacumba (fig. 5).

A ambos lados de la misma se abren 56 nichos, 28 a cada lado, de idénticas dimensiones en centímetros: $80 \times 60 \times 110$. Los nichos estaban sellados en su origen por una losa de piedra. La mayoría de ellos presenta en el dintel una inscripción hierática en negro. Las inscripciones traducidas mencionan los nombres 


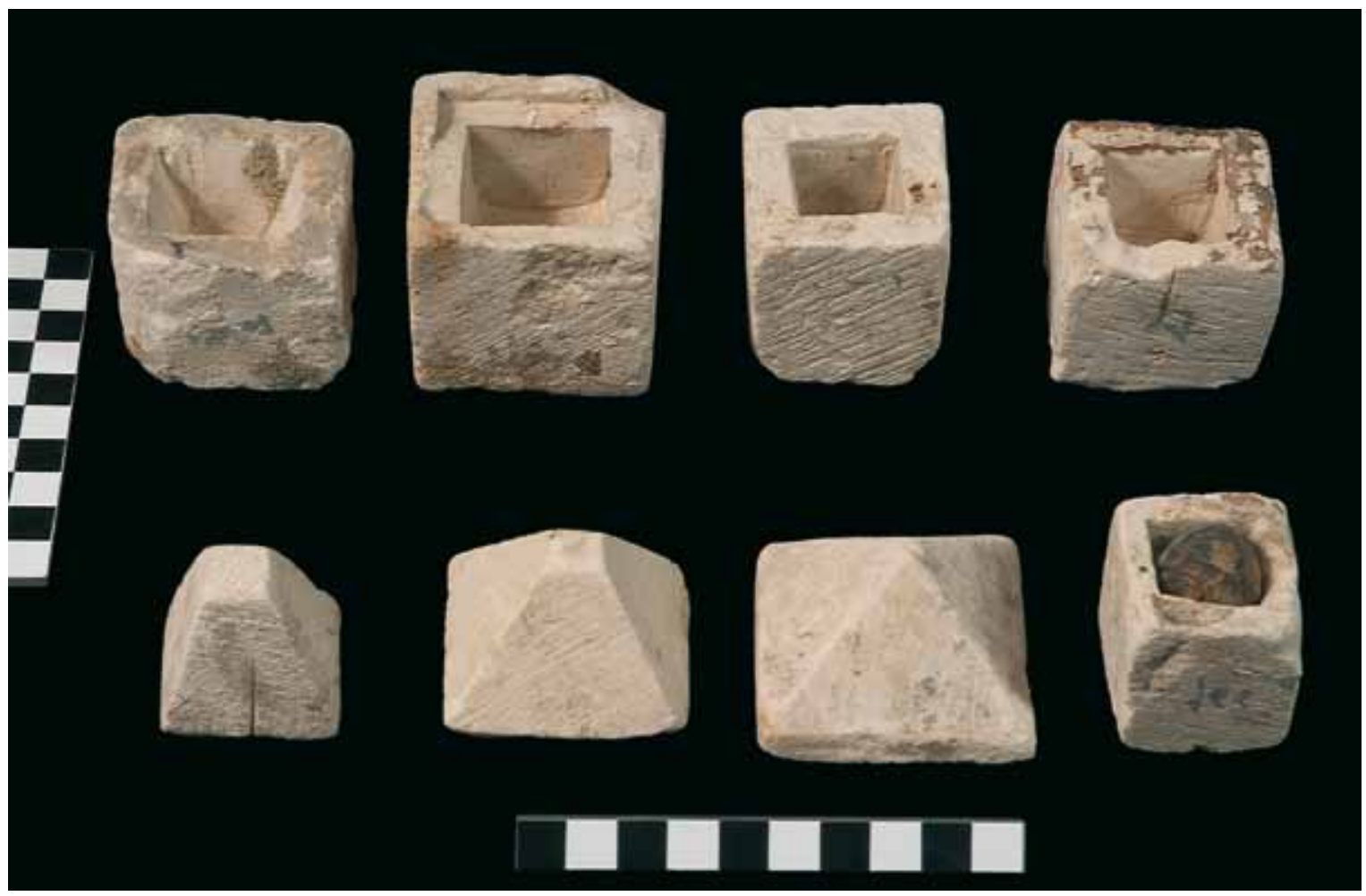

Figura 6. Cajitas de piedra caliza, con inscripciones en demótico, cerradas con tapaderas de formas piramidales. En su interior se encontraron pequeñas bolas de barro recubiertas de vendas

de Ptolomeo VIII Evergetes y de Cleopatra II, así como el nombre particular de cada Osiris y la fecha del año de reinado de los soberanos en que se efectuó el sepelio del simulacro osiriaco. Figura también el nombre de la necrópolis, $\operatorname{Pr}$ - hf , nombre que ya aparece referenciado en los textos del sarcófago de Het (Tumba núm. 1 de la necrópolis saíta), donde se especifica que el propietario ostentaba, entre otros cargos, el de $h m-n t \underline{t} r$ de Bastet en el Pr-ḥf ${ }^{11}$.

Estos textos, que se encuentran actualmente en estudio ${ }^{12}$, permitirán comprender mejor el sector, el objetivo de su construcción y, sobre todo, la historia religiosa del nomo oxirrinquita.
El planteamiento sistemático de excavación de cada uno de los nichos ha permitido, en función de los resultados, identificar algunas partes de la composición y estructura interna de las ofrendas de los mismos. En su interior se depositaban los simulacros de las momias de los Osiris Khentiamentiu, modelados con limo del Nilo juntamente con granos de cereal y una materia resinosa, consolidados con una capa de una sustancia parecida al betún y envueltos con vendas de lino, confeccionados siguiendo las modalidades descritas en las capillas osiriacas del templo de Dendera ${ }^{13}$. Estas figuras tenían el rostro protegido por una máscara y portaban los atributos propios de la divinidad $^{14}$.

11. Línea 4 del texto del sarcófago de Het, Tumba núm. 1. Padró, Amer, Erroux-Morfin, Mascort, Hamza, 2007: 14431454.

12. Los textos están siendo estudiados por Lauren Coulon. 


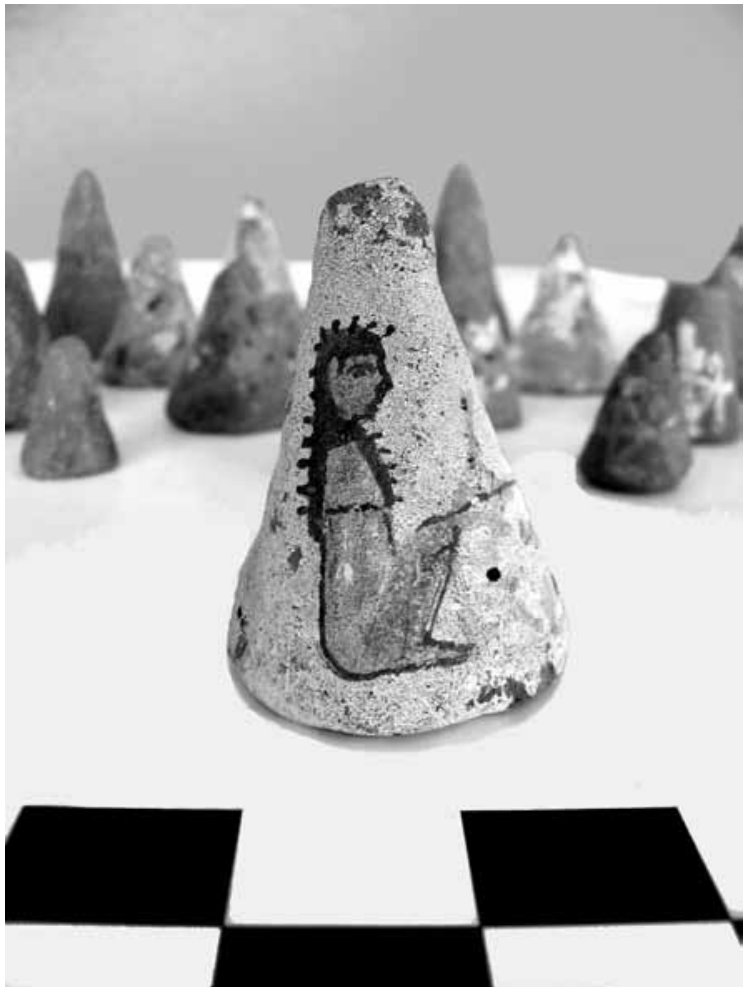

Figura 7. Conos de barro que llevan una inscripción o la representación de la diosa Neith arquera

Entre el ajuar funerario localizado y relacionado con el culto y el ritual de los misterios de Khoiak $^{15}$ destacaremos diversos materiales vinculados con la protección de Osiris:

- Ladrillos mágicos con representaciones de udjat.

- Cajitas de piedra caliza (fig. 6), con inscripciones en demótico, cerradas con unas tapa- deras de formas piramidales. En su interior pequeñas bolas de barro recubiertas de vendas. La mayoría de ellas llevan inscritos, en negro, los nombres de las cuatro diosas leoninas. Se trata de elementos del ritual de las cuatro bolas mágicas, encargado de proteger la momia en los cuatro puntos cardinales ${ }^{16}$.

- Una serie de conos de barro que llevan la representación de la diosa Neith arquera (fig. 7).

- Estatuillas de barro cuya longitud varía entre los 5 y los $20 \mathrm{~cm}$. Algunas de estas figuras están representadas momificadas, otras poseen restos de recubrimiento de oro sobre sus rostros o una inscripción jeroglífica al dorso.

- Figuras de los cuatro hijos de Horus.

Entre el material de ofrenda destacamos la gran cantidad de pequeños platos de cerámica, vasos en miniatura, modelos de panes y pasteles, ofrendas de coronas y frutos de persea ${ }^{17}$, cereal, dátiles y abundantes modelos de mesas de ofrendas votivas, pebeteros, altares y elementos arquitectónicos.

Todo este material permitirá, una vez concluido su estudio, obtener información adicional sobre los ritos osiriacos de la época tardía. En el Osireion culminaba el ritual de los misterios de Osiris para rememorar la muerte y renacimiento del dios. 


\section{Bibliografía}

Bonneau, D.

1964 La crue du Nil. Divinité égyptienne à travers mille ans d'histoire (332 av. J.C. -641 ap. J.C.). Paris.

Cauville, S.

1982 Une offrande spécifique d'Osiris: le récipient à dattes $\left(m^{\top} \underline{d} 3 \mathrm{n} b n r\right), R d E$ 32: 47 64.

Chassinat, E.

1966-68 Le mystère d'Osiris au mois de Khoiak. Le Caire, 2 vols.

Dewachter, M.

1983 Remarques à propos d'un bas-relief ptolémaïque détruit: le bloc Boulogne inv. 117.23, en: De Meulenaere, H. y Limme, L. (eds.): Artibus Aegypti Studia in Honorem Bernardi $V$. Bothmer, Bruxelles : 45-50, n. 3.

Goyon, J.-CL.

1975 Textes mythologiques II. Les révélations du mystère des quatre boules, BIFAO 75 : 349-399.

Коемотн, P.

1994 Osiris et les arbres. Contributions à l'étude des arbres sacrés de l'Egypte ancienne. (AegLeod 3). Liège.
Padró, J.; Amer, H.I.; ErrouX-Morfin, M.; MasCORT, M.; HaMza, M.

2007 Découverte et premiers travaux à l'Osireion d'Oxyrhynchos, en Goyon, J.-Cl.; Cardin, C. (eds.): Proceedings of the Ninth International Congress of Egyptologists. Actes du Neuvième Congrès International des égyptologues, Grenoble 2004, (OLA 150/2), Leuven: II, 1443-1454.

RAVEN, M. J.

1982 Corn-Momies, OMRO 63: 7-38.

SAUNERON, S.

1957 Cinq années de recherches épigraphiques en Egypte, BSFE 24: 45-54.

1968 Villes et légendes d'Egypte. XX: Un nouveau temple ptolémaïque en MoyenneEgypte: Pr-hf, BIFAO 66: 24-27, pls. I-II.

RoNDOT, V.

1997 Alexandre IV Aegos et Ptolémée Ier Sôter au Musée de Besançon, RdE 48: 274-278.

VVAA

1988 Cleopatra's Egypt. Age of the Ptolemies. New York.

ZIEGLER, CH.

1979 A propos du rite des quatre boules, BIFAO 79: 437-439. 


\section{Trabajos de Egiptología Papers on Ancient Egypt}

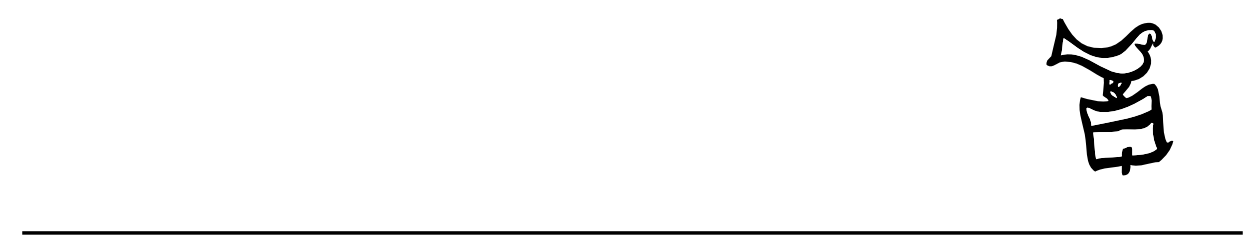

Número 5/2 2009 


\section{Actas \\ III Congreso Ibérico de Egiptología III Congresso Ibérico de Egiptologia}

Editores

Miguel Ángel Molinero Polo Covadonga Sevilla Cueva 


\title{
Editor
}

Miguel Ángel Molinero Polo

Universidad de La Laguna

\section{Consejo Editorial}

\author{
Antonio Pérez Largacha \\ Universidad de Castilla-La Mancha \\ José-R. Pérez-Accino \\ Birkbeck, Universidad de Londres \\ Covadonga Sevilla Cueva \\ Universidad Autónoma de Madrid
}

\section{Comité Científico}

Josep Cervelló i Autuori

Universitat Autònoma de Barcelona

$\mathrm{M}^{\mathrm{a}}$ José lópez Grande

Universidad Autónoma de Madrid

Josep Padró i Parcerisa

Universitat de Barcelona

$\mathrm{M}^{\mathrm{a}}$ Carmen Pérez Die

Museo Arqueológico Nacional, Madrid

Ester Pons Mellado

Museo Arqueológico Nacional, Madrid

José M. Serrano Delgado

Universidad de Sevilla

\section{Colaboradores Editoriales}

Linda Steynor

English editorial assistant

Hervé Mouriacoux

Assistant éditorial pour la langue française 
Trabajos de Egiptología está producida por Isfet. Egiptología e Historia c/ Blanco $1,2^{\circ}$

38400 Puerto de la Cruz

Tenerife-Islas Canarias

España

Maquetación: Proyecto Limón

(C) Autores de los artículos aparecidos

y Consejo Editorial de Trabajos de Egiptología - Papers on ancient Egypt

Depósito Legal: TF-2303-2009

ISSN: $1695-4750$

Imprime: Gráfica Los Majuelos, S.L.L.

imprenta@graficaslosmajuelos.com

Tfno.: 922311455 


\section{Comité Científico \\ III Congreso Ibérico de Egiptología III Congresso Ibérico de Egiptologia}

Miguel Á. Molinero Polo

Universidad de La Laguna

Presidente del Comité Organizador del III Congreso Ibérico de Egiptología

Miembro del Comité Organizador del I Encuentro de Egiptología

Josep Cervelló Autuori

Universitat Autònoma de Barcelona

Presidente del Comité Organizador del II Congreso Ibérico de Egiptologia

José Manuel Galán Allué

Consejo Superior de Investigaciones Cientificas

Director del Proyecto Djehuty, Luxor, Egipto

$\mathrm{M}^{\mathrm{a}}$ Helena Trindade Lopes

Universidad de Lisboa

Directora de la Misión Arqueológica Portuguesa en Menfis

Josep Padró i Parcerisa

Universitat de Barcelona

Director de la Misión Arqueológica de Oxirrinco

Antonio Pérez Largacha

Universidad de Castilla - La Mancha

Miembro del Comité Organizador del I Encuentro de Egiptología

José Ramón Pérez-Accino

Birkbeck College, University of London

Miembro del Comité Organizador del I Encuentro de Egiptología

$\mathrm{M}^{\mathrm{a}}$. Carmen Pérez Díe

Museo Arqueológico Nacional

Directora de la Misión Arqueológica Española en Heracleópolis Magna, Egipto

Covadonga Sevilla Cueva

Universidad Autónoma de Madrid

Miembro del Comité Organizador del I Encuentro de Egiptología 